\title{
Membrane Bistability in Thalamic Reticular Neurons During Spindle Oscillations
}

\author{
Pablo Fuentealba, ${ }^{1}$ Igor Timofeev, ${ }^{1}$ Maxim Bazhenov, ${ }^{2}$ Terrence J. Sejnowski, ${ }^{2,3}$ and Mircea Steriade ${ }^{1}$ \\ ${ }^{1}$ Laboratory of Neurophysiology, Faculty of Medicine, Laval University, Quebec City, Canada; ${ }^{2}$ The Salk Institute, Computational \\ Neurobiology Laboratory, La Jolla; and ${ }^{3}$ Department of Biology, University of California San Diego, La Jolla, California
}

Submitted 27 May 2004; accepted in final form 20 August 2004

Fuentealba, Pablo, Igor Timofeev, Maxim Bazhenov, Terrence J. Sejnowski, Mircea Steriade. Membrane Bistability in Thalamic Reticular Neurons During Spindle Oscillations J Neurophysiol 93: 294-304, 2005. First published August 25, 2004; doi:10.1152/jn.00552.2004. The thalamic reticular (RE) nucleus is a major source of inhibition in the thalamus. It plays a crucial role in regulating the excitability of thalamocortical networks and in generating some sleep rhythms. Current-clamp intracellular recordings of RE neurons in cats under barbiturate anesthesia revealed the presence of membrane bistability in $\sim 20 \%$ of neurons. Bistability consisted of two alternate membrane potentials, separated by $\sim 17-20 \mathrm{mV}$. While non-bistable (common) RE neurons fired rhythmic spike-bursts during spindles, bistable RE neurons fired tonically, with burst modulation, throughout spindle sequences. Bistability was strongly voltage dependent and only expressed under resting conditions (i.e. no current injection). The transition from the silent to the active state was a regenerative event that could be activated by brief depolarization, whereas brief hyperpolarizations could switch the membrane potential from the active to the silent state. These effects outlasted the current pulses. Corticothalamic stimulation could also switch the membrane potential from silent to active states. Addition of QX-314 in the recording micropipette either abolished or disrupted membrane bistability, suggesting $I_{\mathrm{Na}(\mathrm{p})}$ to be responsible for its generation. Thalamocortical cells presented various patterns of spindling that reflected the membrane bistability in RE neurons. Finally, experimental data and computer simulations predicted a role for RE neurons' membrane bistability in inducing various patterns of spindling in target thalamocortical cells. We conclude that membrane bistability of RE neurons is an intrinsic property, likely generated by $I_{\mathrm{Na}(\mathrm{p})}$ and modulated by cortical influences, as well as a factor that determines different patterns of spindle rhythms in thalamocortical neurons.

\section{N T R O D U C T I O N}

The GABAergic neurons of the thalamic reticular (RE) nucleus play a major role in modulating the flow of information through the dorsal thalamus and in the generation of sleep spindles, a thalamically generated rhythm (Steriade et al. 1990). The RE neurons are reciprocally connected with thalamocortical (TC) cells in dorsal thalamic nuclei (Jones 1985), and RE neurons exert powerful inhibitory effects on TC neurons of the dorsal thalamus (Contreras and Steriade 1996; Kim and McCormick 1998b; Thomson 1988).

Despite the relative homogeneity of this nucleus, some data have pointed to differential functional features in various types of RE neurons. For example, a subsample $(\sim 20 \%)$ of RE neurons do not discharge spike bursts to depolarizing current

Address for reprint requests and other correspondence: M. Steriade, Laboratoire de Neurophysiologie, Faculté de Médecine, Université Laval, Québec, G1K 7P4, Canada (E-mail: mircea.steriade@phs.ulaval.ca). pulses even when the membrane potential $\left(V_{\mathrm{m}}\right)$ reaches -100 $\mathrm{mV}$ nor do they fire rebound spike bursts after prolonged hyperpolarizations, thus suggesting that such RE neurons do not express T-type $\mathrm{Ca}^{2+}$ channels (Contreras et al. 1992). This is indeed the case of ventral lateral geniculate cells (Crunelli et al. 1987) that share a common embryological origin with RE neurons and similarly do not project to the cerebral cortex (Jones 1985).

Another difference was found between some RE neurons that, during natural slow-wave sleep, fire spike-bursts lasting $\sim 50-100 \mathrm{~ms}$, and other RE neurons that display during the same behavioral state a prolonged ( $\leq 1$ or $2 s$ ) tonic tail of single action potentials after the spike bursts (compare Figs. 4 and 5 in Steriade et al. 1986). In vitro experiments showed that this prolonged depolarization is due to either a persistent $\mathrm{Na}^{+}$ current, $I_{\mathrm{Na}(\mathrm{p})}$, or a $\mathrm{Ca}^{2+}$-activated nonselective cation current (Kim and McCormick 1998a). The $I_{\mathrm{Na}(\mathrm{p})}$ can generate plateau potentials and membrane bistability (Crill 1996; Gola et al. 1998) that have been demonstrated in various neuronal types of the spinal cord (Bennett et al. 1998), cerebellum (Llinás and Sugimori 1980), dorsal thalamus (Hughes et al. 1999; Toth et al. 1998; Williams et al. 1997), neocortex (Schwindt and Crill 1999), olfactory bulb (Heyward et al. 2001), and hippocampus (Chuang et al. 2000; Fricker and Miles 2000).

If RE neurons displayed exceedingly long or shorter spike bursts during spindle oscillations (Steriade et al. 1986), such differences would presumably be reflected in variant types of inhibition-rebound sequences at the level of target thalamocortical neurons. This hypothesis was at the origin of the present study. The intrinsic firing patterns of RE neurons are fundamental toward the understanding of their role in controlling the electrical activity of target TC neurons. We investigated the membrane properties of RE neurons in vivo and, in particular, the conditions under which long-lasting depolarizing plateaus and prolonged hyperpolarizations can be elicited by intracellular pulses or synaptic volleys. The results show that a subgroup of RE neurons displays membrane bistability, as indicated by two discrete modes of $V_{\mathrm{m}}$, with different responsiveness to cortical inputs. Active membrane properties can amplify and extend in time the influence of both depolarizing and hyperpolarizing inputs. The membrane bistability of RE neurons probably plays an important role in shaping the patterns of spindling oscillation in thalamocortical neurons.

\footnotetext{
The costs of publication of this article were defrayed in part by the payment of page charges. The article must therefore be hereby marked "advertisement" in accordance with 18 U.S.C. Section 1734 solely to indicate this fact.
} 


\section{METHODS}

\section{Animal preparation}

Experiments were performed on adult cats $(2.5-3.5 \mathrm{~kg})$, anesthetized with pentobarbital $(25 \mathrm{mg} / \mathrm{kg}$ ip). When the cats showed the signs of deep anesthesia, the animals were paralyzed with gallamine triethiodide and artificially ventilated with control of the end-tidal $\mathrm{CO}_{2}$ concentration at $\sim 3.5 \%$. Body temperature was maintained at $36-38^{\circ} \mathrm{C}$. The depth of anesthesia was continuously monitored by electroencephalography (EEG), and additional doses of anaesthetic were administered at the slightest tendency toward low-voltage and fast EEG rhythms. At the end of experiments, animals were given a lethal dose of pentobarbital $(50 \mathrm{mg} / \mathrm{kg}$ iv).

\section{Electrophysiological recordings}

Current-clamp intracellular recordings from RE neurons (rostral and rostrolateral sector of the nucleus) and TC neurons from the ventrolateral (VL) nucleus were performed using glass micropipettes (DC resistance, 30-60 M $\Omega$ ). To avoid breaking of recording micropipettes, the cortex and white matter overlying the head of the caudate nucleus were removed by suction. The pipettes entered $\sim 3 \mathrm{~mm}$ through the caudate nucleus to reach the thalamic RE nucleus. Pipettes were generally filled with $3 \mathrm{M}$ solution of $\mathrm{K}$-acetate and, in some experiments, with $50 \mathrm{mM}$ of QX-314 (the DC resistance was identical to that of $\mathrm{K}$-acetate-filled pipettes). The stability of intracellular recordings was ensured by cisternal drainage, bilateral pneumothorax, hip suspension, and by filling the hole over the thalamus with $4 \%$ agar solution. A high-impedance amplifier with active bridge circuitry was used to record and inject current inside the cells. Most intracellular recordings included in the database lasted for periods $>30 \mathrm{~min}$. Simultaneous extracellular recordings were performed using up to four tungsten electrodes (10-15 M $\Omega$ ) inserted through the caudate nucleus, with an inter-electrode distance of $\sim 0.5 \mathrm{~mm}$. To determine the membrane potential $\left(V_{\mathrm{m}}\right)$ of RE neurons, DC offset was adjusted constantly before and after every recording; the bridge was also adjusted through intracellular recordings. Once the recording was finished, the recording pipette was withdrew from the recording site $(10-20 \mu \mathrm{m})$ to avoid possible DC offsets due to the extracellular environment close to the neurons and to establish a reference considered as zero $(0 \mathrm{mV})$ for the intracellular recordings.

Cortical activity was monitored in all experiments by EEG recordings from areas 4 and 6 , corresponding to intracellularly recorded RE neurons.

\section{Data analysis}

All data were analysed under Igor pro 4.0 (Wametrics). Because the correct determination for $V_{\mathrm{m}}$ was central for this study, precautions were taken during both experiments and analysis. Action potentials during active states did not affect significantly $V_{\mathrm{m}}$ measurements because of the short duration of action potentials in RE neurons (1 ms) and the very high sampling rate of intracellular recordings $(20 \mathrm{kHz})$, which guarantees a sub-millisecond time resolution. Because the time spent by a neuron to generate spikes is very short $( \pm 1 \mathrm{~ms})$ and the spike after hyperpolarization (AHP) lasts for $\pm 10 \mathrm{~ms}$, the effects of neuronal firing in the generation of histogram of the membrane potential distribution should be negligible. Moreover, preliminary analyses were carried out in digitized filtered waves $(0-40 \mathrm{~Hz})$ to eliminate spikes from the intracellularly recorded signals. $V_{\mathrm{m}}$ distributions of such signals proved to be very much similar to the non-filtered signals and displayed only small shifts in the active peak $(2-4 \mathrm{mV})$ for the cases of resting and hyperpolarized conditions. For depolarized states, in which RE neurons undergo sustained (tonic) discharge, filtered signals showed a narrower $V_{\mathrm{m}}$ distribution when compared to non-filtered signals, with small shifts to depolarized values (2-4 mV). Therefore most analyses were performed directly on non-filtered waves.

Membrane potential distributions during intracellular recordings were assessed by histograms. Intracellular recordings were sampled at high sampling rate $(20 \mathrm{kHz})$ allowing a high resolution in time of intracellular events and membrane potential changes. Histograms were built by segmenting the range of the data (e.g., membrane potential) into equal sized number of classes. According to the Scott's rule (Scott 1979) the number of classes or interval size $(k)$ in a histogram is $k=3.5 s n^{-1 / 3}$, where $s$ is the $\mathrm{SD}$ and $n$ is the total number of points in the sample. Because we used a high sampling rate and long periods of recordings for analysis, the number of points was in the order of $10^{5}-10^{6}$. In this case, the interval size should be $\sim 0.5$ $\mathrm{mV}$. However, for reasons of simplicity, we chose a slightly bigger binsize, meaning $1 \mathrm{mV}$ for all histograms. This binsize did not produce significant differences compared to others $(0.25,0.5,0.75$; data not shown).

\section{Computer simulations}

In modeling studies, we examined single-compartment models of $\mathrm{RE}$ and TC cells which included voltage- and $\mathrm{Ca}^{2+}$-dependent currents described by Hodgkin-Huxley kinetics. For both RE and TC cells, we considered a fast $\mathrm{Na}^{+}$current, $I_{\mathrm{Na}}$, a fast $\mathrm{K}^{+}$current, $I_{\mathrm{K}}$, a low-threshold $\mathrm{Ca}^{2+}$-dependent current, $I_{\mathrm{T}}$ (Huguenard and McCormick, 1992; Huguenard, 1996), and a $\mathrm{K}^{+}$leak current, $I_{\mathrm{KL}}=G_{\mathrm{KL}}(V$ $\left.E_{\mathrm{KL}}\right)$ A model of hyperpolarization-activated cation current $I_{\mathrm{H}}(\mathrm{Mc}-$ Cormick and Pape, 1990), taking into account both voltage and $\mathrm{Ca}^{2+}$ dependencies (Destexhe et al. 1996b), was also included in TC cells. A persistent $\mathrm{Na}^{+}$current, $I_{\mathrm{Na}(\mathrm{p})}$, was included to RE cells to model bistability of the responses. For $I_{\mathrm{Na}(\mathrm{p})}, I_{\mathrm{Na}(\mathrm{p})}=G_{\mathrm{Na}(\mathrm{p})} \mathrm{m}(V-50)$, $\mathrm{d} m / \mathrm{d} t=\left(m_{\infty}-m\right) / 0.2, m_{\infty}=1\{1+\exp [-(V+42) / 5]\}$ (Alzheimer et al. 1993). The expressions for voltage- and $\mathrm{Ca}^{2+}$-dependent transition rates for all currents are given in Bazhenov et al. (1998, 2000).

$\mathrm{GABA}_{\mathrm{A}}$ and AMPA synaptic currents were modeled by first-order activation schemes (Destexhe et al. 1994). GABA $_{B}$ receptors were modeled by a higher-order reaction scheme that took into account activation of $\mathrm{K}^{+}$channels by $\mathrm{G}$ proteins (Destexhe et al. 1994, 1996a; Dutar and Nicoll, 1988). The equations for all synaptic currents are given in Bazhenov et al. (1998, 2000).

A thalamic network was also modeled and consisted of a onedimensional two-layer array of $M \mathrm{RE}$ and $M$ TC neurons, where $M$ was varied between 20 and 64 . In most of the simulations, the connection fan out was \pm 3 cells for $\mathrm{GABA}_{\mathrm{A}}$-mediated RE-RE synapses; \pm 3 cell for AMPA-mediated TC-RE synapses; \pm 3 cells for $\mathrm{GABA}_{\mathrm{A}^{-}}$and $\mathrm{GABA}_{\mathrm{B}}$-mediated RE-TC synapses. Other radii of synaptic interconnections were used to test the sensitivity of the results.

\section{RES ULTS}

All neurons recorded intracellularly $(n=57)$ and extracellularly $(n=13)$ within the rostral pole and rostrolateral sector of the RE nucleus were identified by accelerando-decelerando spike-bursts (see insets in Fig. $1 A$ for intracellular and Fig. 4 for extracellular recordings). The accelerando-decelerando pattern refers to the initially increasing, but rapidly decreasing, inter-spike intervals that occur within every single burst of action potentials in RE neurons. This is the typical firing pattern of RE neurons' spike bursts during spindling, as described during natural slow-wave sleep (Domich et al. 1986; Steriade et al. 1986) as well as intracellularly in anesthetized animals (Contreras et al. 1993). 


\section{Differences between bistable and non-bistable RE neurons}

A subgroup of intracellularly recorded neurons (23\%, 13 of 57) displayed a sustained depolarization during EEG spindles (Fig. 1A, left). This plateau potential was initiated at the beginning of each spindle sequence and persisted during its whole duration. At variance, the remaining RE neurons fired
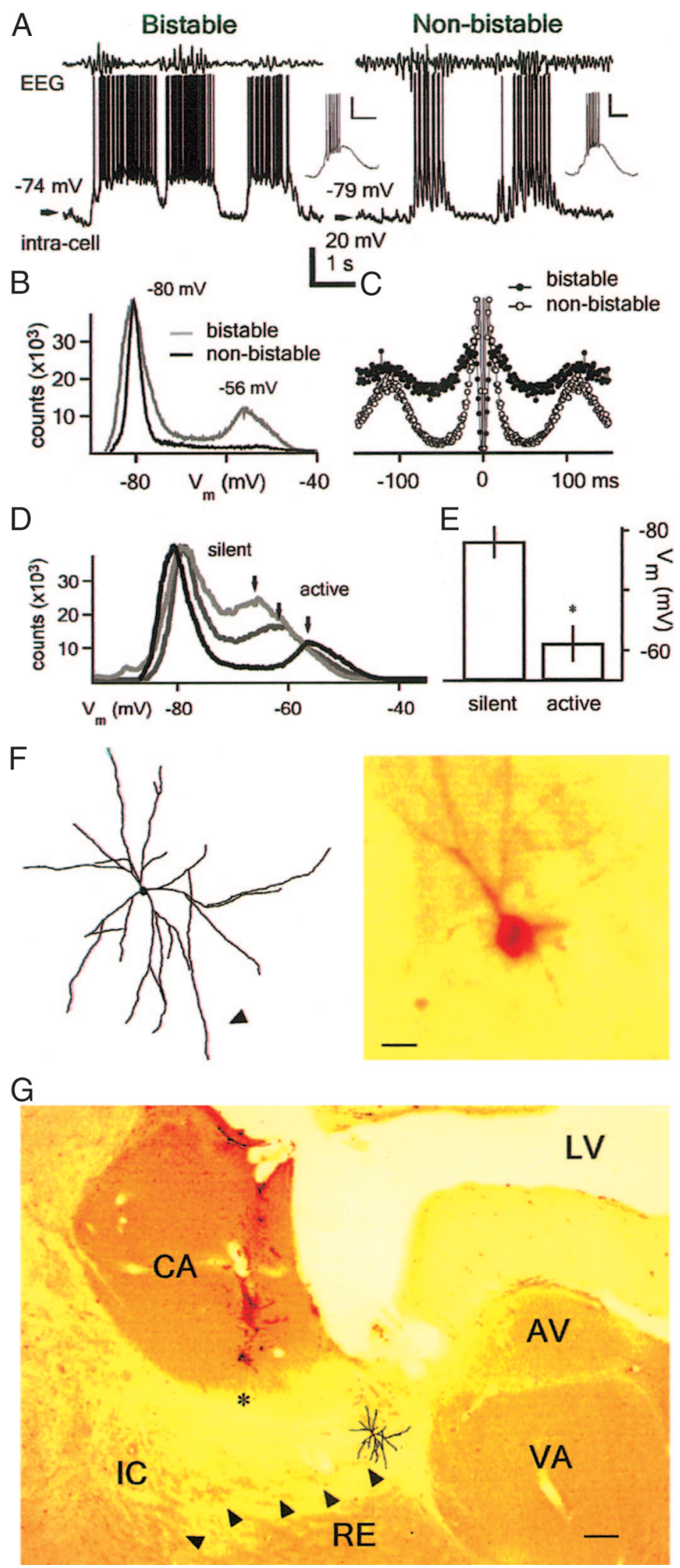

spike bursts interrupted by clear-cut hyperpolarizing potentials (Fig. 1A, right), as described in previous studies on RE neurons. Histograms of $V_{\mathrm{m}}$ distribution showed two discrete peaks in the former group of RE cells (at $\sim-80 \mathrm{mV}$ and $\sim-56 \mathrm{mV}$ for the left neuron in Fig. 1A), representing the sustained depolarization during spindles and the silent phase, whereas only one peak was detected in the remaining RE neurons (Fig. $1 B$ ). Thus neurons displaying two discrete peaks in their $V_{\mathrm{m}}$ distribution were defined as revealing membrane bistability (see Heyward et al. 2001). Autocorrelograms of action potentials fired by non-bistable neurons displayed clear lags of $\sim 110$ ms (Fig. 1C), consistent with firing in the frequency range of spindles $(\sim 9 \mathrm{~Hz})$. At variance, bistable neurons showed much less pronounced peaks and troughs (Fig $1 C$ ).

In those cells where membrane bistability was detected, it was a graded property because it displayed a variable range of values between resting and active periods. Figure $1 D$ shows the $V_{\mathrm{m}}$ distributions for three different RE neurons. All these bistable neurons were at a resting $V_{\mathrm{m}}$ of $\sim-80 \mathrm{mV}$; however, the second peak differed for each cell not only in its position but also in its relative amplitude ( $\downarrow$ Fig. $1 D)$. Bistable cells spontaneously generated two discrete $V_{\mathrm{m}} \mathrm{s}$ (Fig. 1E): the first one represented the active state, with relatively depolarized $V_{\mathrm{m}}$ $[-60.8 \pm 3.1(\mathrm{SD}) \mathrm{mV}]$, coincident with spindle activity and around the threshold for action potential generation; the second was a silent state, with a relatively hyperpolarized $V_{\mathrm{m}}$ $(-77.7 \pm 2.7 \mathrm{mV})$, occurring during interspindle lulls. The difference between the two states was $16.8 \pm 3.5 \mathrm{mV}$ (range: 13-22 $\mathrm{mV}, n=9$; Fig. $1 E$ ). By contrast, non-bistable cells displayed the well-known waxing and waning pattern of spindle oscillation (see Fig. 1A, right) and their $V_{\mathrm{m}}$ distribution presented a single peak at $\sim-80 \mathrm{mV}$ (see Fig. $1 B$ ).

Morphological reconstruction of some bistable neurons showed typical features of RE neurons, with fusiform shape lying parallel to the surface of the dorsal thalamus and very long dendrites (Fig. $1 F$ and $G$ ), suggesting no morphological differences between bistable and non-bistable neurons.

FIG. 1. Membrane bistability in reticular (RE) neurons during spontaneously occurring spindles. A: cortical electroencephalographic (EEG) and intracellular recordings from 2 RE neurons. Typical low-threshold spike bursts of each of these RE cells are expanded in insets; scale is same for both neurons. Bistable neuron displayed sustained depolarizations throughout spindle waves. Non-bistable neuron fired spike bursts, separated by phasic hyperpolarizations, during spindling. Scale bars: $50 \mathrm{~ms}, 20 \mathrm{mV}$. B: histograms of $V_{\mathrm{m}}$ distribution from bistable and non-bistable cells in $A$, taken from a 5 -min period of spontaneous activity. Only bistable neurons presented bimodal $V_{\mathrm{m}}$ distributions. Bin size, $1 \mathrm{mV}$. $C$ : autocorrelograms of action potentials for the same periods used in $B$. Non-bistable cells discharged in the spindle frequency $(\sim 9$ $\mathrm{Hz}$ ), showing clear peaks at $\sim \pm 110$-ms delay, whereas bistable cells showed less marked correlation with spindle frequency. Bin size, $1 \mathrm{~ms}$. $D$ : Bistability is a graded property. Different bistable RE neurons (represented by different gray tones) displayed diverse patterns of $V_{\mathrm{m}}$ distributions, but all showed 2 discrete peaks though at different positions. Note the constancy of the 1st peak (silent) and the variable position of the second peak (active, $\downarrow$ ). Bin size, 1 $\mathrm{mV}$. E: silent and active states during membrane bistability presented different membrane potentials (mean $\pm \mathrm{SD}, n=9$ ); ${ }^{*} P<0.001 . F$ : intracellularly stained (Neurobiotin) bistable RE neuron located in the rostral sector of the nucleus. Photograph (right) and reconstruction (left). $\boldsymbol{\Delta}$, the axon to the dorsal thalamus. Calibration bar $=20 \mu \mathrm{m}$ for RE neuron in the photograph and 100 $\mu \mathrm{m}$ for the reconstructed RE neuron. $G$ : microphotograph of the section where the cellular soma was recovered. Reconstruction shows the relative position of the neuron. $\boldsymbol{\Delta}$, rostrolateral sector of the RE nucleus. *, the stimulating electrode in the internal capsule (IC). Scale bar: $500 \mu \mathrm{m}$. AV, anteroventral nucleus; CA, caudate nucleus; LV, lateral ventricle; VA, ventroanterior nucleus 
Similarly to spontaneously generated spindles, bistability was seen in cortically elicited spindles. Histograms of $V_{\mathrm{m}}$ distributions during evoked spindling showed that only bistable RE neurons displayed a clear-cut two-peak pattern of membrane bistability, and autocorrelograms of action potentials showed that bistable neurons did not consistently discharge in the frequency range of spindles (Fig. 2).

\section{Voltage dependency of membrane bistability}

We assessed the voltage dependence of bistability in RE neurons $(n=6$; Fig. 3$)$. The $V_{\mathrm{m}}$ distributions represent the proportion of time spent at each $V_{\mathrm{m}}$ (excluding action potentials) in resting condition (with no current injection) and during the injection of negative or positive steady current through the pipette. During resting $(0 \mathrm{nA})$, the distribution was bimodal, with two peaks reflecting the silent state $(-79 \mathrm{mV}$, i.e. interspindle lulls) and the active state $(-62 \mathrm{mV}$, i.e. spindles, Fig. $3 B)$. Positive current injection $(+0.2 \mathrm{nA})$ abolished bistability and generated sustained firing with no repolarization to the resting state (Fig. $3 A$ ). The $V_{\mathrm{m}}$ distribution showed a single peak (at $-59 \mathrm{mV}$ ), which rapidly decayed up to $-70 \mathrm{mV}$; more negative values of $V_{\mathrm{m}}$ were virtually absent. With injection of negative current $(-0.2 \mathrm{nA})$, the bimodal distribution of $V_{\mathrm{m}}$ was also abolished, and a single peak remained $(-89 \mathrm{mV})$, falling sharply up to $-80 \mathrm{mV}$ and decaying smoothly at more positive values (Fig. $3 C$ ). The abolition of bistability could be reached with current injections as small as $-0.1 \mathrm{nA}$ (not shown).

Thus injection of different levels of steady current showed that bistability was exclusively displayed under the resting condition, i.e., when no current was injected. The $V_{\mathrm{m}}$ of bistable neurons was asymmetrically affected, depending on the sign of the injected current. Negative current produced a hyperpolarization with higher amplitude than the depolariza-
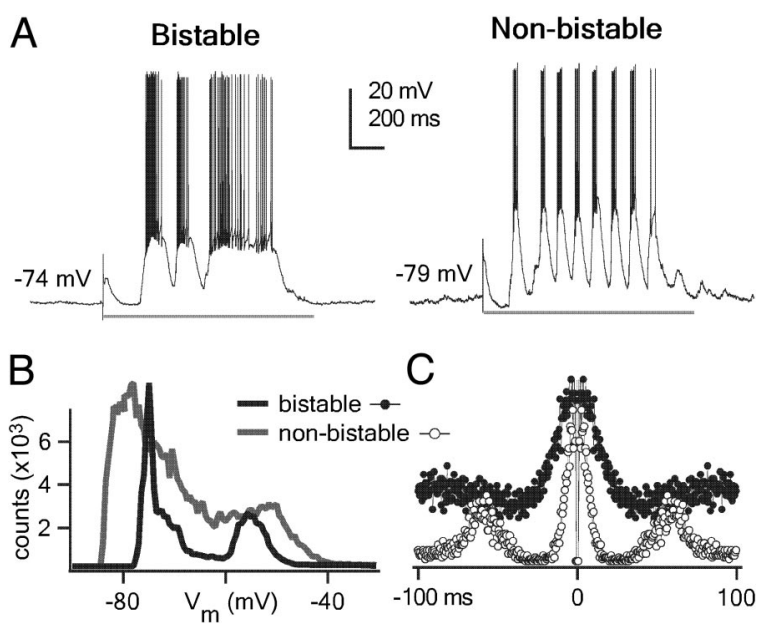

FIG. 2. Membrane bistability can be triggered by corticothalamic inputs. A: intracellular recordings of $2 \mathrm{RE}$ neurons, displaying spindles triggered by electrical stimulation of the internal capsule. One of them presents a plateau potential (bistable), whereas the other neuron shows a typical sequence of spike bursts during spindling. The gray line below both recordings indicates the periods used to compute the histograms in $B$. B : histograms of $V_{\mathrm{m}}$ distribution during spindle waves from bistable and non-bistable cells in $A$ taken from 50 evoked spindles. Only the bistable neuron presented 2 discrete peaks in the $V_{\mathrm{m}}$ distribution. Bin size, $1 \mathrm{mV}$. Distributions were significantly different (Kruskal-Wallis, $H=51.5, P<0.001$ ). $C$ : autocorrelograms of action potentials in both neurons; bin size, $1 \mathrm{~ms}$.
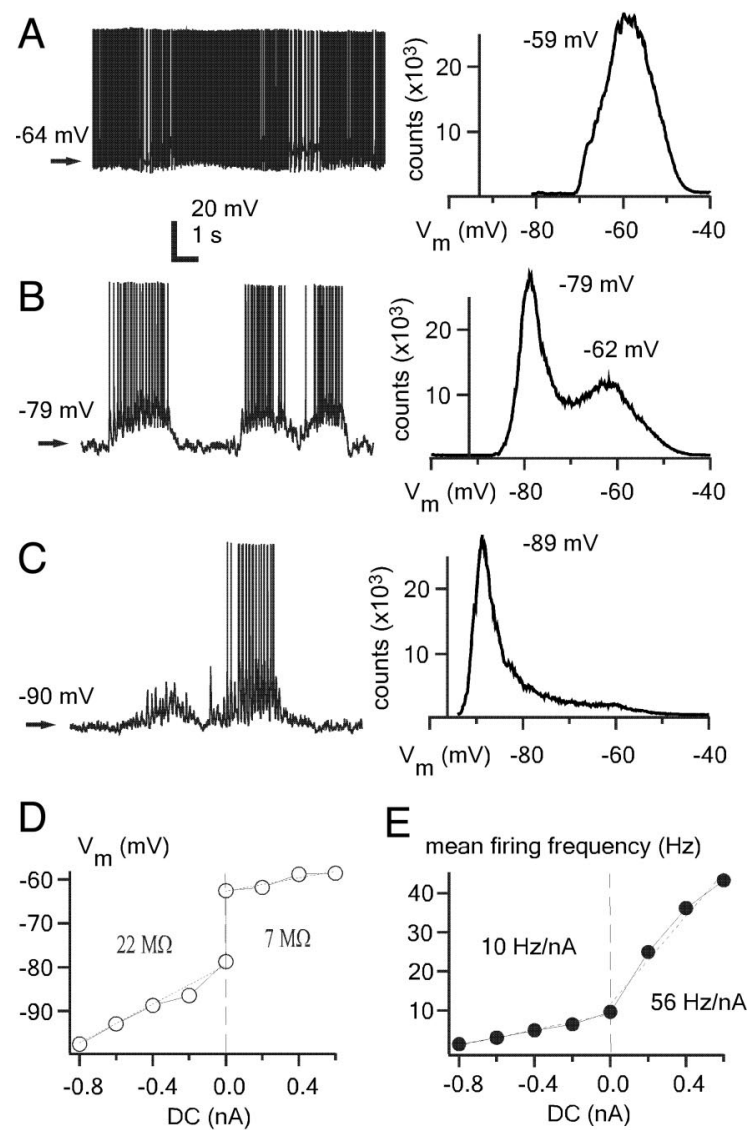

FIG. 3. Membrane bistability is voltage dependent. Intracellular recording $\left(A-C\right.$, left) and histograms of $V_{\mathrm{m}}$ distributions (right) for a RE neuron held at different levels of DC (3-min period of intracellular recording in each case). $A$ : positive current injection $(+0.2 \mathrm{nA})$ depolarized the $V_{\mathrm{m}}$ to $-64 \mathrm{mV}$ and caused a sustained, tonic firing (left). Only a single mode was present in such cases for $V_{\mathrm{m}}$ distribution (right). $B$ : without current $(0 \mathrm{nA},-79 \mathrm{mV})$, it was possible to distinguish a bimodal $V_{\mathrm{m}}$ distribution $(r i g h t)$. $C$ : negative current injection $(-0.2 \mathrm{nA},-90, \mathrm{mV})$ was equally efficient in abolishing bistability (right) even though firing occurred during spindles (left). $D$ : summary plot of the relation between injected current (DC) and the resulting membrane potential $\left(V_{\mathrm{m}}\right)$. The resting level $(0 \mathrm{nA})$ is the only 2 point case in the $V_{\mathrm{m}}$ axis $(-79$ and $-62 \mathrm{mV})$ and constitutes an asymmetric axis for the apparent input resistance, $R_{\mathrm{in}}(7 \mathrm{M} \Omega$ for positive DC and $22 \mathrm{M} \Omega$ for negative DC). E: summary plot of the relation between injected current (DC) and mean firing frequency of the cell. The resting level marks an asymmetric axis for the gain in firing frequency (56 $\mathrm{Hz} / \mathrm{nA}$ for positive DC and $10 \mathrm{~Hz} / \mathrm{nA}$ for negative DC). $R_{\mathrm{in}}$ and gain in firing frequency were calculated as the slope for the linear fitting in $D$ and $E$, respectively. Each $V_{\mathrm{m}}$ point is the mean of a Gaussian fitting to the histogram for each DC value. Histograms' bin size, $1 \mathrm{mV}$.

tion induced by the same amount of current with opposite sign (Fig. 3D). This supposed an asymmetric change in input resistance $\left(R_{\mathrm{in}}\right)$ measured from the resting $V_{\mathrm{m}}$. Actually, in a sample of six bistable RE neurons, the $R_{\text {in }}$ was fourfold higher for hyperpolarized values of $V_{\mathrm{m}}$ than for the depolarized ones $(25.3 \pm 6.2$ and $6.4 \pm 4.0 \mathrm{M} \Omega$, respectively). On the other hand, $R_{\text {in }}$ was linearly related to $V_{\mathrm{m}}$ in non-bistable neurons (not shown). Comparing $R_{\text {in }}$ between non-bistable and bistable neurons (during periods of negative DC), showed no significant difference $(25.3 \pm 6.2$ and $31.5 \pm 8.5 \mathrm{M} \Omega$, for bistable and non-bistable groups, respectively; $P>0.5$ ). An inverse relation was found for the mean firing frequency. Even though the $R_{\text {in }}$ was lower during states associated with membrane depolarization, tiny changes in injected current produced large changes in firing frequency (Fig. $3 E$ ). In fact, the gain in firing 
frequency was much higher for depolarized membrane values compared to changes in the hyperpolarized values $(84.7 \pm 69.3$ and $18.7 \pm 11.6 \mathrm{~Hz} / \mathrm{nA}$, respectively; $P<0.05 ; n=6)$. These results indicate that membrane bistability in $\mathrm{RE}$ neurons is strongly voltage dependent, this would be consistent with the generation of bistability by intrinsic mechanisms.

To investigate whether bistability was an artefact arising from intracellular recordings, simultaneous extracellular recordings of two or more RE neurons were performed $(n=13)$. Figure 4 shows one of those experiments in which two RE neurons were recorded simultaneously and identified by their spike bursts with accelerando-decelerando firing patterns. Differences in firing patterns during spontaneous spindles between the two cells could be first seen by visual inspection. Whereas one neuron only fired rhythmic spike bursts (cell 1), the other neuron also displayed tonic tails of discharges after the bursts (cell 2). Tonic tail refers to low-frequency spikes (typically $<100 \mathrm{~Hz}$ ) generated by some RE neurons, which fire in single mode toward the end of spindle waves. Two other cells presented similar features as cell 2 (then, 3 of the total 13), with initial spike bursts followed by tonic tails. Plots of instantaneous firing frequency during spindles showed that cell 1 exclusively discharged high-frequency bursts $(>300 \mathrm{~Hz})$ during the spindle period, whereas cell 2 fired slower bursts $(\sim 200$ $\mathrm{Hz}$ ) followed by tonic firing up to $100 \mathrm{~Hz}$ (Fig. 4C). Consistent with these results, the interspike interval (ISI) histogram for a long period of spontaneous activity showed for non-bistable neurons, like cell 1, a narrow distribution that peaked at $3 \mathrm{~ms}$

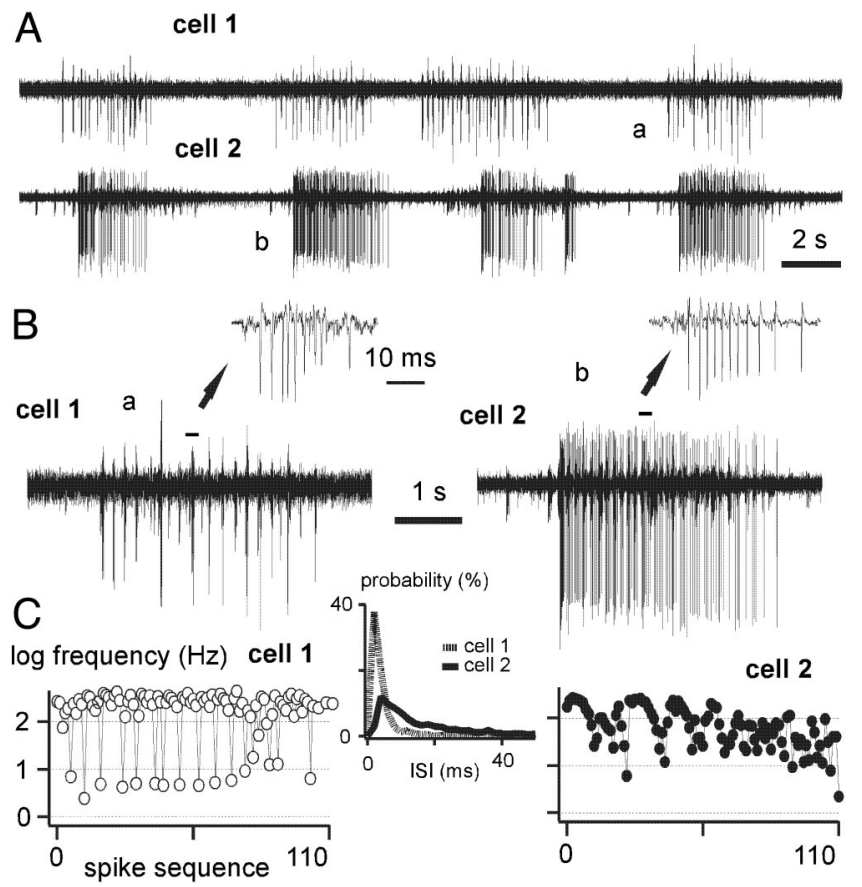

FIG. 4. Simultaneous extracellular recordings of non-bistable and bistable RE neurons show different firing patterns during spindles. To avoid corticofugal influences, recordings were made in decorticated cats. A: dual extracellular recordings of RE neurons (cells 1 and 2). B: 1 spindle period chosen from the above panel, for each RE neuron. Visual inspection reveals the presence of tonic firing in cell 2 (right). Spike bursts displaying the accelerando-decelerando pattern identified both RE neurons (see $\uparrow$ and insets in $B$ ). $C$ : semilogarithmic plot for firing frequency in cells 1 and 2 during spindle sequences shown in $B$. Note tonic spikes $(\sim 20-100 \mathrm{~Hz})$ only in cell 2 . Inset: interspike intervals for a 5 -min period of recording during spontaneous activity in each cell; bin size, $1 \mathrm{~ms}$.
( $\sim 350 \mathrm{~Hz})$ and decayed rapidly up to $\sim 10 \mathrm{~ms}(100 \mathrm{~Hz})$, indicative that tonic firing was virtually absent (inset, Fig. 4C). A much wider ISI distribution was seen for neurons like cell 2, which peaked at $4 \mathrm{~ms}(250 \mathrm{~Hz})$ and decayed smoothly up to 40 ms $(25 \mathrm{~Hz})$, which reflected the tonic firing (inset, Fig. 4C). The same analysis carried out for extracellular recordings was applied for intracellular recordings, showing that only bistable neurons displayed an important component of tonic firing in their discharge pattern (data not shown).

\section{Intrinsic mechanisms generate bistability}

The idea that intrinsic mechanisms are implicated in the generation of bistability was supported by experiments showing that current pulses $(200 \mathrm{~ms}, 1 \mathrm{nA})$ were able to activate the plateau potential characteristic for bistability with very similar kinetics to the spontaneous one. The initiation of bistability induced by current pulses was twice as fast as when compared to the spontaneous one, as shown by the exponential fitting to the rising phase of the plateau potential ( $\tau$ of activation, $\sim 21$ and $\sim 48 \mathrm{~ms}$, respectively; $n=3$, not shown).

The artificial generation of membrane bistability by injection of current pulses of different durations and amplitudes was investigated in nine bistable RE neurons held at different values of $V_{\mathrm{m}}$. Intracellular current pulses were applied at low frequencies (0.3 to $1 \mathrm{~Hz})$. Depolarizing current pulses $(2 \mathrm{nA})$ applied at rest $(0 \mathrm{nA})$ were able to generate an initial burst of action potentials, followed by tonic spikes that outlasted the current pulse (Fig. $5 A$ and $B$ ). Under steady hyperpolarization $(-2 \mathrm{nA})$, the depolarizing current pulses failed to elicit an outlasting plateau potential even though the pulse amplitude was greatly increased (Fig. $5 C$ and $D$ ). The same failure was obtained by using shorter current pulses (Fig. $5 E$ ). The plot in Fig. $5 F$ summarizes these results, showing the duration of the plateau potential outlasting the response evoked by the current pulse at the resting $V_{\mathrm{m}}(-80 \mathrm{mV})$, the absence of such a plateau under steady hyperpolarization (reaching $-90 \mathrm{mV}$ ), and an intermediate level with plateau potential outlasting the duration of the current pulse, although not as long as in the resting $\left(V_{\mathrm{m}},-85 \mathrm{mV}\right)$.

Similarly to the initiation of the active state, the termination of the active period could be ascribed to intrinsic mechanisms. Thus brief current pulses were able to mimic termination of active states. The termination of the active states was fitted with an exponential function. The average $(n=10)$ of such fitting functions showed that termination evoked by current pulses was twice faster than spontaneous termination $(\tau$ of inactivation 75 and $131 \mathrm{~ms}$, respectively; $n=3$ ), similar to what was found for the activation process (not shown). The presence of such a mechanism for termination of plateau potentials suggests that this active state is maintained by voltage-dependent mechanisms, which can be deactivated by hyperpolarization.

After a relatively long silent period ( $\sim 2 \mathrm{~s})$, a brief positive current pulse was able to evoke an active period (Fig. 6, top) very similar to the one generated after a relatively short silent period ( $\sim 0.4 \mathrm{~s}$; Fig. $6 A$, middle). Similar results were found in other two neurons. The plot in Fig. $6 A$ bottom, shows no relation between the duration of the preceding silent period and the duration of the active period generated by the current pulse. Current pulses that were not able to produce an outlasting 

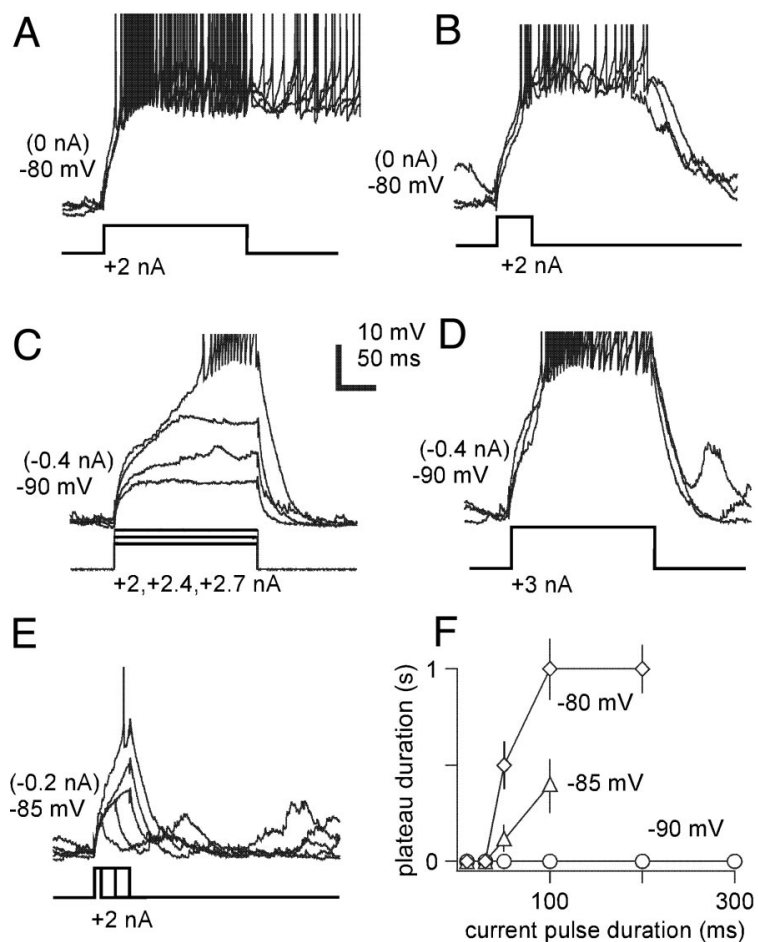

FIG. 5. Active states in membrane bistability evoked by depolarizing current pulses in RE neurons are graded and voltage dependent. $A$ : current pulse (200 ms, $2 \mathrm{nA})$ generated an outlasting active state at rest $(0 \mathrm{nA}) . B$ : shorter current pulses $(50 \mathrm{~ms}, 2 \mathrm{nA})$ were also able to elicit outlasting active states but of shorter duration. $C$ and $D$ : hyperpolarization $(-2 \mathrm{nA})$, bringing the $V_{\mathrm{m}}$ to $-90 \mathrm{mV}$, abolished the ability of current pulses to generate outlasting active state in the same neuron even though their amplitudes were increased $(+2$, $+2.4,+2.7$, and $+3 \mathrm{nA}$ ). $E$ : very short current pulses (10 and $30 \mathrm{~ms}$ ) were not able to elicit active responses under slight hyperpolarization (DC $-1 \mathrm{nA}$ ). Short current pulses $(50 \mathrm{~ms})$ could trigger a spike occasionally. $F$ : summary plot for the current pulse duration vs. the duration of the evoked plateau outlasting the stimulus. Note graded properties for intermediate levels of membrane polarization $(-85 \mathrm{mV})$.

active state were considered as failures. There was also no relation between the duration of the preceding silent period and the likelihood of failure (Fig. 6A bottom).

Brief negative current pulses, which were able to terminate the active state, were effective regardless of the duration of the preceding active state as either short- or long-lasting plateaus could be equally shunted (Fig. $6 B$ ). Similar results were found in other two neurons. The probability for a given current pulse (100 ms, $2 \mathrm{nA}$ ) to terminate an active state was considerably high $(80 \%$, Fig. $6 B$ bottom). However, there was a relation between the duration of shunting produced by the hyperpolarizing current pulse and the preceding active period. Longlasting active periods $(>3 \mathrm{~s})$ were shunted for longer periods than short-lasting $(<2$ s) active states $(936.7 \pm 370.4$ and $412.5 \pm 247.5 \mathrm{~ms}$, respectively; $P<0.01$ ). Similarly to the initiation of active periods, the likelihood of shunting failures was not dependent on the duration of the preceding active period (Fig. $6 B$ bottom).

\section{Absence of bistability in RE neurons recorded with QX-314}

To elucidate some of the ionic mechanisms underlying the origin of bistability, and given the antecedent that TTX blocks plateau potentials in RE neurons (Kim and Mccormick 1998a), intracellular recordings were performed with QX-314 (50 mM) in the micropipette. From the pool or recorded neurons $(n=$ 19), only in one case was it possible to recognize bistable membrane behavior (see DISCUSSION). In that case, the RE neuron displayed clear plateau potentials, consisting of burst and tonic discharges during the early period of the recording (Fig. 7A and $B$ ). The $V_{\mathrm{m}}$ of this neuron presented the characteristics of bistability with a double-peak in the distribution histogram (early in Fig. 7C). After a few minutes, QX-314 started to diffuse and action potentials decreased both in amplitude and frequency. As time elapsed, not only spike generation was affected, but also the expression of the plateau potential (Fig. 7). The decrease in the sustained depolarization during spindles was reflected as a change in the $V_{\mathrm{m}}$ distribution of the cell because the secondary peak of active states was abolished (late in Fig. 7C). Measuring the area of depolarization during spindle periods showed a threefold decrease in the presence of QX-314 in the recording pipette, after $40 \mathrm{~min}$ of recording (40993.1 \pm 18607.2 and $13499.2 \pm 3548.8 \mathrm{mV} * \mathrm{~ms}$, $P<0.05,2$ and $40 \mathrm{~min}$; respectively; Fig. 7D).

In other neurons, we were not able to detect bistable behavior during the early period of recordings with QX-filled pipettes. Therefore we compared the depolarization area during the spindle sequences in bistable neurons and in some of the neurons recorded with QX-314 $(n=5)$. At hyperpolarized $V_{\mathrm{m}} \mathrm{s}$, the areas of depolarization during spindles were very similar in bistable and QX-314-recorded neurons $(10.1 \pm 1.4$
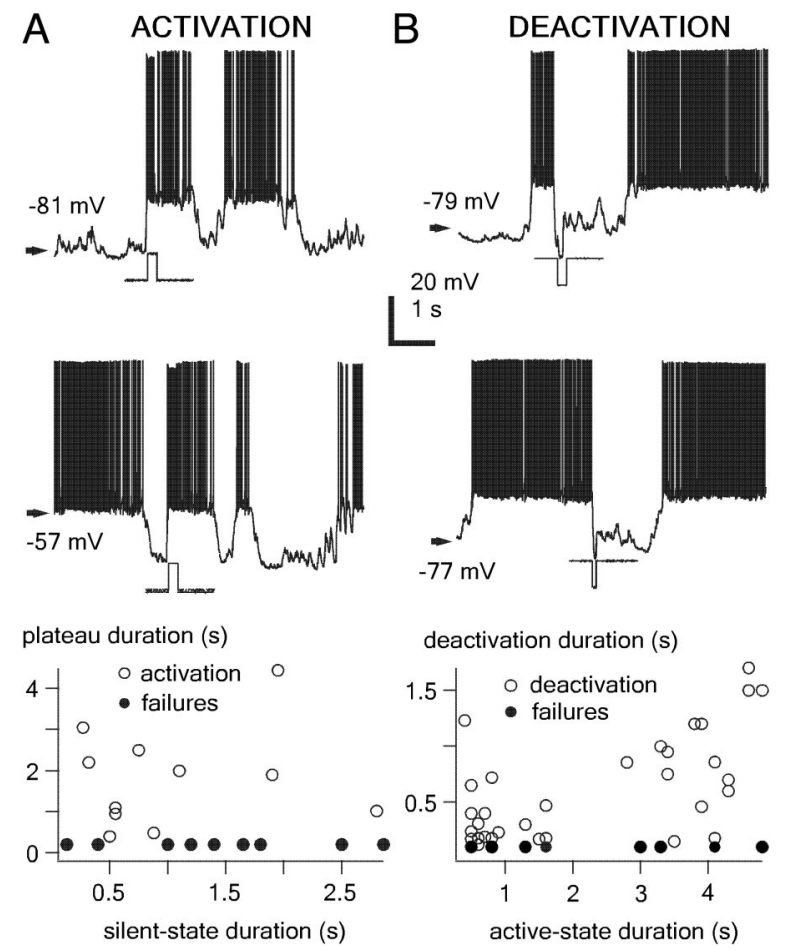

FIG. 6. Intrinsic membrane properties are involved in the generation, maintenance, and termination of active states in membrane bistability. A: depolarizing current pulses $(200 \mathrm{~ms},+2 \mathrm{nA})$ were able to generate active states, characteristic of membrane bistability in RE neurons, independent on the duration of the previous silent period (bottom). Note that failures in generating an active state were also independent on the history of the cell. $B$ : hyperpolarizing current pulses ( $200 \mathrm{~ms},-1$ and $-2 \mathrm{nA}$ ) were effective in shunting the active states. Note (bottom) that long-lasting active periods $(>3$ s) were shunted for longer periods than short lasting $(<2 \mathrm{~s})$ active periods; and failures were independent on the ongoing active state duration. 

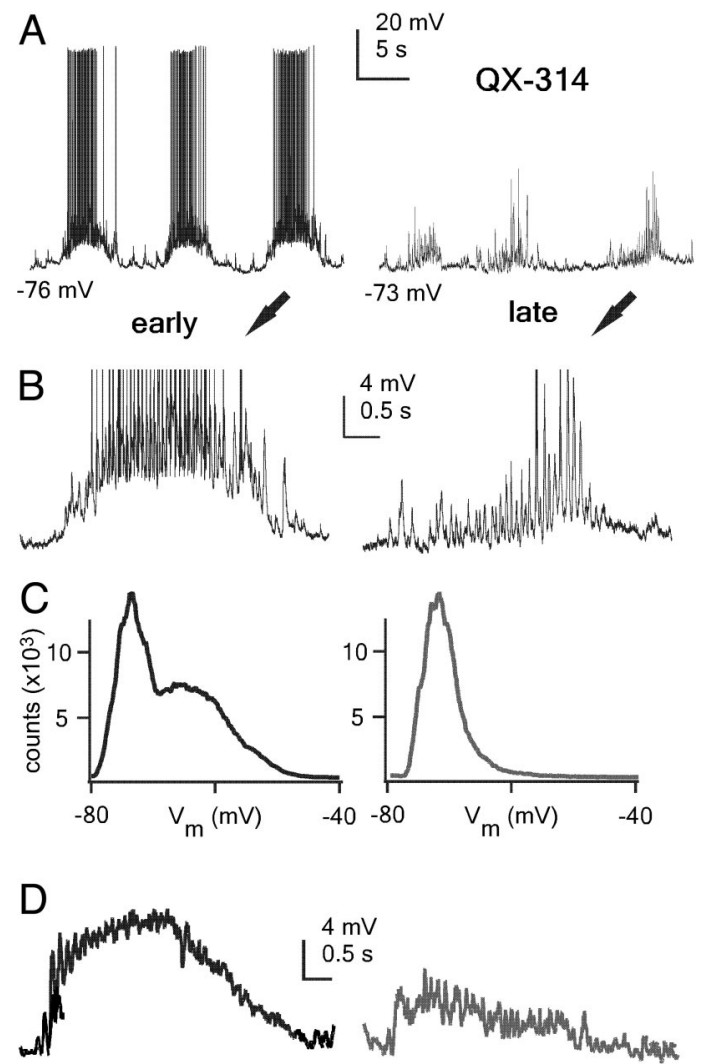

FIG. 7. Ionic basis of membrane bistability. A: RE neuron recorded with QX-314-filled pipette $(50 \mathrm{mM})$ shown at 2 different periods of recording: early ( $2 \mathrm{~min}$ ) and late $(40 \mathrm{~min}) . B$ : expanded period of the recording shown in $A$. Each period is indicated $(\rightarrow)$ and corresponds to a complete spindle oscillation. $C: V_{\mathrm{m}}$ distribution for the 2 periods of recording, each histogram computed from a 2-min episode of spontaneous activity. Bin size, $1 \mathrm{mV}$. $D$ : average $(n=$ 20 ) of spindle oscillations for the 2 (early and late) periods of recording shows a neat decrease in plateau potentials during the late period. Spikes were removed by filtering digitized signals $(<100 \mathrm{~Hz})$.

and $9 \pm 1.5$ normalized units, respectively); however, when neurons were at the resting $V_{\mathrm{m}}$, bistable cells displayed their characteristic active states, increasing considerably the depolarization area, twofold larger than in recordings with QX-314 $(16.6 \pm 2$ and $8 \pm 1.3$ normalized units, respectively; $P=$ 0.0001; not shown). These results suggest that QX-314 either abolishes or disrupts bistability in RE neurons.

\section{Membrane bistability of RE neurons modulates their synaptic responsiveness}

Responses to stimulation of the internal capsule where compared during silent and active states in bistable RE neurons $(n=5)$. During silent states, corticofugal volleys elicited short-latency, subthreshold excitatory postsynaptic potentials (EPSPs) with little variability in amplitude. During active states, the $V_{\mathrm{m}}$ was depolarized by $\sim 20 \mathrm{mV}$ and responses to stimulation, crowned by action potentials, where of two types: either short and fixed-latency spikes or EPSPs that elicited spikes with much longer and variable latencies (Fig. $8 A-C$ ). By raising the stimulation strength, action potentials could be elicited even during the silent state (not shown). The threshold intensities for spike generation were quantified for silent as well as for active states. The half-maximal probability of spike generation was reached at a stimulation intensity of $130 \mu \mathrm{A}$ for the active period and $164 \mu \mathrm{A}$ during the silent state (Fig. 8D). This shows that stimulus intensities that are sufficient to produce spikes during the active state did not evoke action potentials in the silent state. Thus the active state represents a condition of increased responsiveness to synaptic inputs because it brings the membrane potential close to the firing threshold, allowing incoming inputs to trigger action potentials.

Various spindling patterns in thalamocortical neurons may reflect non-bistable or bistable activity patterns of RE neurons

The main output of the RE nucleus is to the dorsal thalamus, the neurons of which receive a powerful, cyclic inhibition from GABAergic RE neurons during spindles (Steriade et al. 1990, 1993). To assess a possible effect of membrane bistability in RE neurons on spindle waves, we performed intracellular recordings from TC cells $(n=21)$, identified by their short spike bursts $(<30 \mathrm{~ms})$ and their characteristic sequence of inhibitory postsynaptic potentials (IPSPs) during spindle waves (Fig. 9A).

Visual inspection revealed the presence of a sub-group of neurons (14\%, 3 of 21$)$ displaying different types of spindles, compared to all other neurons. One of those cells (cell 2 in Fig. 9) is shown for comparison with a typical TC neuron (cell 1 in Fig. 9). As known, during spindles most TC neurons (like cell 1) display regular and powerful IPSPs due to the inhibitory action of RE neurons during spindles, which hyperpolarize the neuronal membrane, thus de-inactivating the $I_{\mathrm{T}}$ that, in turn,
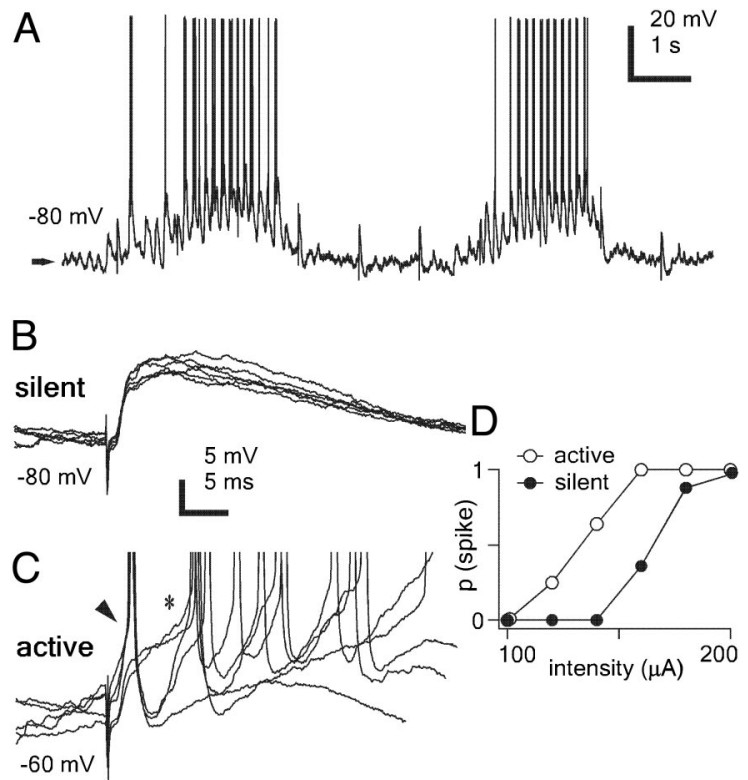

FIG. 8. Membrane bistability modulates synaptic responsiveness of RE neurons. A: intracellular recording of RE neuron displaying both silent and active periods as stimulated from the internal capsule $(140 \mu \mathrm{A}, 1 \mathrm{~Hz}) . B$ : superimposed responses $(n=5)$ during silent states, consisting on shortlatency and low-variability excitatory postsynaptic potentials. $C$ : superimposed responses $(n=5)$ during active states, consisting on short-latency, fixed spikes $(\boldsymbol{\Delta})$ and spikes with variable latencies $(*)$. $D$ : summary plot for the stimulation intensity and the probability of evoking and action potential. Note a shift in the curve for active states, which require lower stimulation intensities. Spike probability was calculated as the fraction of stimuli that elicited an action potential. 

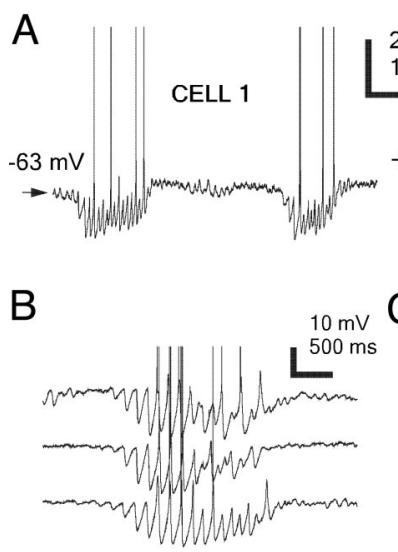

D

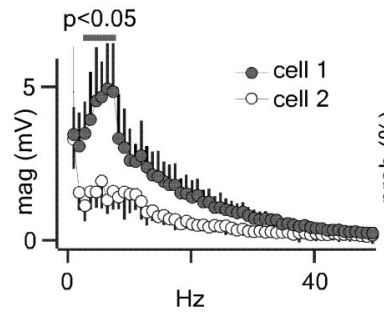

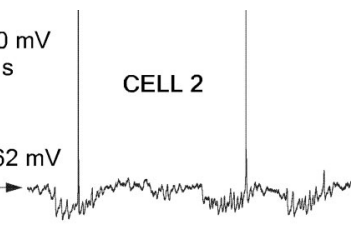

$2 \mathrm{mV}$

$50 \mathrm{~ms}$

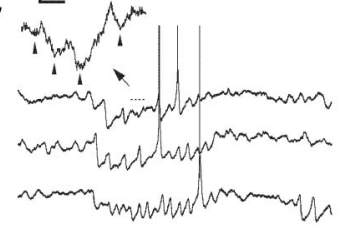

$E$

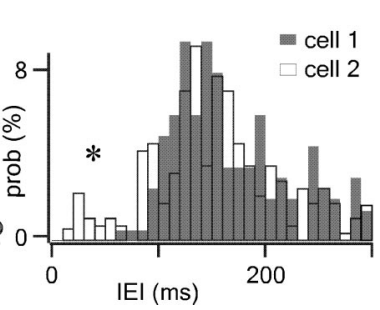

FIG. 9. Different spindling patterns in thalamocortical (TC) cells reflect various firing patterns in RE neurons. $A$ : intracellular recordings of $2 \mathrm{TC}$ neurons (VL nucleus) during spindle activity. $B$ and $C$ : 3 different spindle sequences for each of the above cells. Note highly regular activity and early rebound bursting in cell 1. Inset in cell 2 shows 3 inhibitory postsynaptic potentials (IPSPs) $(\uparrow)$ at much higher frequency $(\sim 20 \mathrm{~Hz})$ than the usual frequency range of spindles (see text). $D$ : average of frequency spectrums of spindle periods $(n=10$, mean $\pm \mathrm{SD})$ in both cells 1 and 2 neurons. Bin size, $1 \mathrm{~Hz}$. Note a clear peak around $7 \mathrm{~Hz}$ for cell 1. E: histograms of inter-event intervals (IEI) for presumably IPSPs $(n=400)$ in both cells 1 and 2 during spindle waves. Bin size, $10 \mathrm{~ms}$. Note the presence of a tail at short intervals $(<100 \mathrm{~ms})$ for cell $2(*)$.

may generate a burst of action potentials. Such canonical TC neurons initiate rebound bursts after the initial three to four IPSPs during spindle periods (Fig. 9B). On the other hand, neurons like cell 2 presented irregular sequences of IPSPs superimposed on a tonic hyperpolarization during spindles; a spike burst was not present before the second half of the spindle sequence and such bursts usually occurred toward the very end of the spindle (Fig. 9C).

In fact, the frequency spectrum of the signals extracted by fast Fourier transform analysis showed spindles in the frequency range of $\sim 7-10 \mathrm{~Hz}$ to be much more represented in thalamocortical neurons like cell 1 than in neurons like cell 2 (Fig. 9), consistent with the irregularity seen in IPSPs occurring during spindles in cell 2. Spindle-related IPSPs were selected and their intervals of incidence measured. Histograms of inter-event intervals (IEIs) in thalamocortical cell 1 showed that IPSPs during spindles were mostly distributed in the 130to $150-\mathrm{ms}$ interval, consistent with the spindle frequency at $\sim 7$ $\mathrm{Hz}$ (Fig. 9E). At variance, thalamocortical neurons like cell 2 presented a tail shifted to shorter intervals (Fig. 9E*), indicating the presence of faster activities in some thalamocortical neurons. Indeed, intracellular recordings of neurons like cell 2 revealed the presence of small-amplitude events, presumably IPSPs, during spindle waves, reflecting higher frequencies $(\sim 20 \mathrm{~Hz})$ than the expected frequency at $7-10 \mathrm{~Hz}$ for these periods (see $\boldsymbol{\Delta}$ in inset, Fig. 9C). Because IPSPs occurring in

thalamocortical neurons during spindle oscillations are exclusively generated by RE neurons, the activity of thalamocortical neurons could be well regarded as the mirror image or the output of the RE nucleus, which drives the activity of the dorsal thalamus during spindle oscillations. Therefore these results are consistent with the idea of two different functional groups of RE neurons projecting to the dorsal thalamus, providing different patterns of inhibition.

\section{Computer simulations predict a role for membrane bistability of RE neurons in modulating thalamic oscillations}

Our results with QX 314 and previous studies performed in slices (Kim and Mccormick 1998a) suggested that $I_{\mathrm{Na}(\mathrm{p})}$ could contribute to the generation of prolonged depolarizing states in RE neurons. The role of $I_{\mathrm{Na} \text { (p) }}$ was further studied in computer simulations. In a first stage, RE neurons were modeled to determine if inclusion of $I_{\mathrm{Na}(\mathrm{p})}$ in their repertoire was enough to produce membrane bistability and, furthermore, if such behavior would have an impact on oscillations in TC neurons. Then thalamic networks containing RE and TC neurons were modeled.

Computer simulations of typical RE neurons displayed an initial high-frequency spike burst followed by a lower-frequency train of action potentials upon stimulation with a positive current pulse (Fig. 10A, non-bistable). Inclusion of $I_{\mathrm{Na}(\mathrm{p})}$ in the same model was able to generate a sustained firing pattern, which outlasted the duration of the current pulse (Fig. $10 \mathrm{~A}$, bistable), a typical feature of membrane bistability in these cells (see previous figures). As $I_{\mathrm{Na}(\mathrm{p})}$ had a strong effect in the initial bursting response of RE neurons (not shown), the values for $I_{\mathrm{T}}$ were decreased in those neurons, including the $I_{\mathrm{Na}(\mathrm{p})}$ (Fig. 10A). This way, another characteristic of bistable RE neurons was mimicked: the slightly lower frequency discharges compared to typical non-bistable RE neurons (plot in Fig. 10A; see also Fig. 4). Activation and deactivation of the plateau potential, distinctive of membrane bistability, were also seen in RE neurons modeled with the inclusion of $I_{\mathrm{Na}(\mathrm{p})}$. Stimulation with a brief positive current pulse to RE neurons in resting conditions induced transition to the active, depolarized state, which outlasted the duration of the stimulus and remained indefinitely in the model (bottom black trace, Fig. $10 A)$. Such an active state or plateau potential could be terminated by the injection of the same current pulse but with opposite sign (bottom gray trace, Fig. 10A). In this situation, $V_{\mathrm{m}}$ returned to initial resting conditions.

Next we modeled a thalamic network consisting of RE and TC neurons. To mimic the proportion found in experiments, only a few RE neurons presented $I_{\mathrm{Na} \text { (p) }}$ and, thus, membrane bistability (see METHODS). Thalamic oscillations presented different patterns in TC neurons, depending on the presence or absence of membrane bistability in RE neurons. For the majority of RE neurons, bursting within spindle frequency was evident during active oscillatory periods (Fig. 10B, 2 top traces). On the other hand, bistable RE neurons exhibited prolonged firing by far exceeding the durations of individual LTSs ( 60 ms; Fig. 10B, 2 bottom traces), consistent with a low correlation with spindle-frequency activities (see Fig. 1). These different patterns of activity in RE neurons had a differential effect of target TC neurons, depending on the connectivity in the reciprocal network. Note that TC cells 


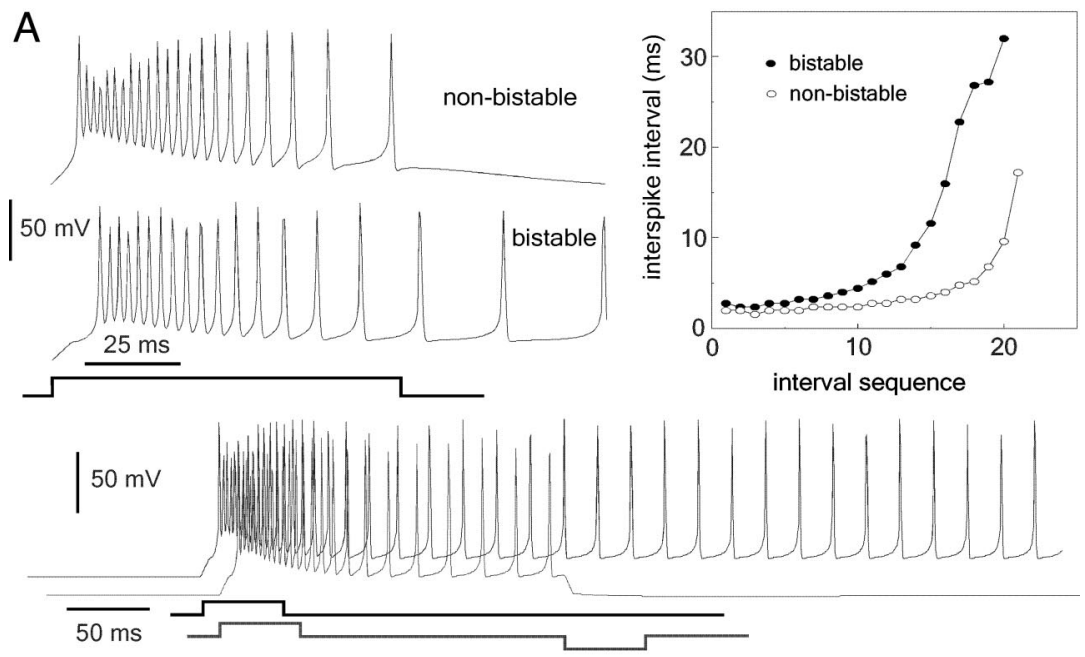

B

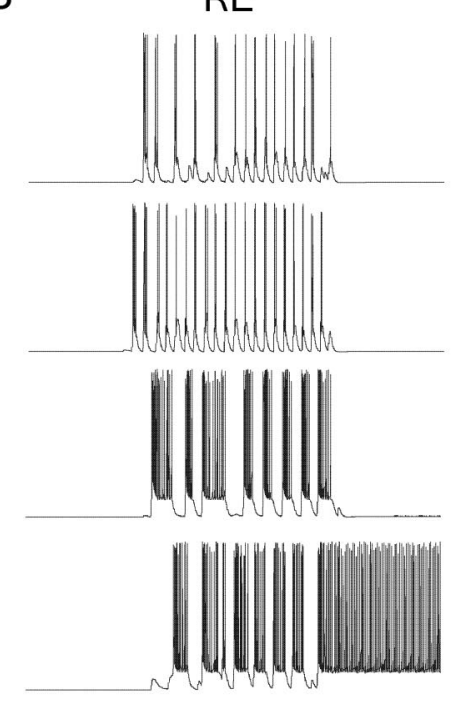

TC
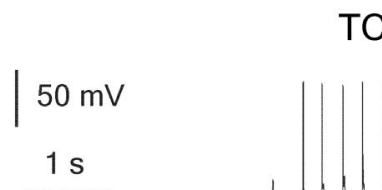

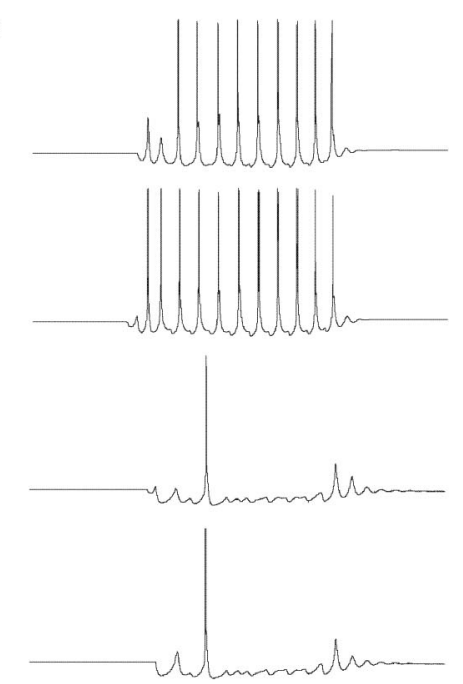

FIG. 10. Computational models predict that membrane bistability of RE neurons modulates patterns of spindle oscillations in TC neuron. A: single-compartment models of bistable and non-bistable RE neurons. Bistability was obtained by inclusion of $I_{\mathrm{Na}(\mathrm{p})}$ in non-bistable neurons. Nonbistable $g_{\mathrm{T}}=3 \mathrm{mS} / \mathrm{cm}^{2}, I_{\mathrm{Na}(\mathrm{p})}=0.3 \mathrm{mS} / \mathrm{cm}^{2}$, bistable $g_{\mathrm{T}}=$ $0.75 \mathrm{mS} / \mathrm{cm}^{2}, g_{\mathrm{Na}(\mathrm{p})}=0.6 \mathrm{mS} / \mathrm{cm}^{2}$ for higher traces; $g_{\mathrm{T}}=$ $1 \mathrm{mS} / \mathrm{cm}^{2}, g_{\mathrm{Na}(\mathrm{p})}=0.6 \mathrm{mS} / \mathrm{cm}^{2}$ for lower traces. Resting $V_{\mathrm{m}}$ $-80 \mathrm{mV}$. Right plot reflects interspike intervals for both types of cells, notice non-bistable neurons to fire at higher frequencies. $B$ : RE and TC neurons during active periods in a simulated thalamic network (26 RE cells and 26 TC cells). See also text. receive projections from multiple RE neurons; therefore, the final effect on spindling pattern was a combination between those multiple inhibitory inputs. Accordingly, TC neurons receiving preferentially projections from non-bistable RE neurons displayed robust, regular oscillations with rebound spike bursts in most cases (Fig. 10B, 2 top traces). Conversely, TC cells receiving inputs mainly from bistable RE neurons showed irregular rhythms, associated with very low rebound discharges (Fig. 10B, 2 bottom traces; compare to experimental data in Fig. 9C). In fact, the spatial-temporal pattern of activity in the modeled thalamic network showed a few TC neurons that were hyperpolarized and did not fire during the active periods of this type of thalamic oscillations (not shown).

\section{I S C U S S I O N}

The main results of the present study are as follows. 1) A subspopulation of the recorded cells, consisting in $\sim 23 \%$ of cat RE neurons displayed membrane bistability during spindles in vivo. The bistability consisted of two discrete $V_{\mathrm{m}}$ levels: an active state (plateau potential) and a silent state, separated by $\sim 17 \mathrm{mV}$. 2) The membrane bistability only occurred at the resting $V_{\mathrm{m}}$, was an intrinsic property of RE neurons, and was modulated by synaptic activity. 3) Bistability did not appear in neurons recorded with QX-314. 4) Bistable and non-bistable RE neurons could determine different patterns of spindling in target thalamocortical neurons. And 5) computer simulation supported the idea that membrane bistability in RE neurons is generated by the activation of $I_{\mathrm{Na}(\mathrm{p})}$ and that such bistable activity is able to modulate the pattern of thalamic spindle oscillations.

The active state in bistable RE neurons has the characteristics of plateau potentials. Such behavior could be generated either by intrinsic membrane properties or a particular synaptic activity in the thalamocortical network. The membrane bistability here reported seems to be intrinsically generated as is the case described in multiple structures in the central nervous system (see INTRODUCTION). That membrane bistability is an intrinsic, voltage-dependent property of RE neurons was indicated by its presence only at the resting $V_{\mathrm{m}}$, through induction of prolonged depolarizing plateaus by brief intracellular current pulses, and by termination of these plateaus by hyperpolarizing current pulses. Our results indicate that intrinsic mechanisms are involved in the generation, maintenance, and termination of active states during membrane bistability. While 
the active state represents a depolarized plateau potential that may be de-activated by hyperpolarization, the silent state is maintained until sufficient depolarization occurs to initiate an active depolarization toward the active state. The transition from the silent to the active state proceeds exponentially. The present data showed that small-amplitude EPSPs are ineffective in spike generation during the silent state. However, when EPSPs are strong enough, they give rise to action potentials even during the silent state (data not shown), and the transition to an active state may occur.

The two different modes of $V_{\mathrm{m}}$ bistability are associated with different degrees of neuronal responsiveness. The active state is around the threshold for action potential generation, whereas the silent state is subthreshold. A broader range of depolarizing inputs' amplitudes may be processed during the silent state, without the generation of a short-latency and stereotyped spike, than in the active state. On the other hand, small-amplitude EPSPs, which are ineffective during the silent state, may well trigger action potentials during the active state. When excitatory inputs occurring during the silent state are strong enough, transition to the active state might occur. Such transition amplifies the voltage change produced by transient depolarizing signals.

Actually, corticofugal volleys elicit complex depolarizing responses in RE neurons composed by several EPSPs followed by all-or-none events resembling dendritic spikes or, in less numerous RE neurons, presumably unitary dendritic spikes (Contreras et al. 1993). The dendritic spikes may contribute to the generation of spindle oscillations by boosting distal inputs and depolarizing the soma as well as by triggering dendritic low-threshold spikes (Huguenard and Prince, 1992; Destexhe et al. 1996b; Huguenard, 1996) that are crucial in the generation of spindle oscillations. Thus although an intrinsic membrane property, bistability may strongly be modulated by synaptic activity.

Intracellular recordings of RE neurons in vivo present technical problems due to instability. In the majority of cases, the initial period of recording (3-5 $\mathrm{min})$ is unstable, presenting continuous changes in the $V_{\mathrm{m}}$. To maintain the neuron, this period was necessarily performed under negative current injection. Because membrane bistability is present only at resting conditions and is abolished by current injection in the pipette, it was not possible to detect bistable behavior in neurons recorded under QX-314. During the few minutes that are necessary to stabilize the recording, QX-314 is already acting on its target conductances. This is the probable reason to explain the fact that upon current removal, and resting conditions recovered, bistable behavior was not seen in most neurons recorded with QX-314-filled pipettes. The only neuron in which bistability was seen under QX-314 conditions (see Fig. 7) was stable from the very early period of recordings (1-2 min), and both action potentials and plateau potentials were rapidly affected.

The marked effect of QX-314 suggests that generation of bistability requires activation of voltage-gated $\mathrm{Na}^{+}$channels. However, QX-314 also blocks low- and high-voltage-activated $\mathrm{Ca}^{2+}$ currents (Talbot and Sayer, 1996) and $\mathrm{K}^{+}$currents (Svoboda et al. 1997; Paré and Lang, 1998) as well as hyperpolarization-activated currents (Perkins and Wong, 1995). Therefore the relative contribution of $\mathrm{Na}^{+}$and other QX-314sensitive channels in generating bistability is not yet clear.
Still, TTX bath application in perigeniculate (RE) thalamic slices blocked plateau potentials, suggesting that $I_{\mathrm{Na}(\mathrm{p})}$ may generate such activities (Kim and McCormick, 1998a). Furthermore computer simulations of RE neurons predicted that by the inclusion of $I_{\mathrm{Na}(\mathrm{p})}$, otherwise typical RE neurons became bistable. Thus the ionic basis of bistability in RE neurons seem to be different than those in TC neurons, where a steady-state residual ("window") component of $I_{\mathrm{T}}$ is responsible for signal amplification and bistable behavior (Williams et al. 1997).

Membrane bistability in a subgroup of RE neurons might play an important role in different patterns of spindles displayed by thalamocortical neurons. In vivo (Steriade et al. 1985; Timofeev and Steriade, 1996) and in vitro (Bal et al. $1995 \mathrm{a}, \mathrm{b})$ intracellular studies have revealed the cellular mechanisms responsible for spindle generation, demonstrating that prolonged, rhythmic IPSPs in TC cells during spindles are time-locked and generated by spike bursts fired by RE neurons. Consequently, any change in the bursting pattern of RE neurons would affect their targets, thalamic relay neurons. Intracellular recordings of TC cells showed at least two different patterns during spontaneously occurring spindles. Although simultaneous recordings of RE and TC neurons have not been performed in the present experiments, the two patterns displayed by cells 1 and 2 in Fig. 9 may be related to the actions exerted by non-bistable and bistable RE neurons, respectively. Indeed, non-bistable neurons fired stronger bursts with higher intra-bursts frequencies, which are assumed to generate deeper and longer IPSPs in TC neurons, giving rise to the usual frequency range of spindles under barbiturate anesthesia, $\sim 7-10 \mathrm{~Hz}$. By contrast, IPSPs with lower amplitudes and higher frequency, $\leq 20 \mathrm{~Hz}$ (see inset in Fig. 9C) are likely to be mainly generated by single action potentials in RE neurons, as they occur during the depolarizing plateau in bistable cells. In either case, the crucial role of RE neurons in initiating spindles, even in the absence of feed-back excitatory effects from TC neurons, is shown by the absence of rebound bursts with fast action potentials after the first three or four IPSPs in relay cells (Timofeev et al. 2001). Supporting these results, computational models of thalamic networks, including bistable RE neurons, showed a significant shaping of thalamic oscillations in TC neurons by bistable RE neurons. Although spindles are initiated in the RE nucleus (Steriade et al. 1987), this oscillation is maintained by reciprocal actions between RE and TC neurons (Steriade et al. 1993; von Krosigk et al. 1993; Bal et al. 1995a, b).

\section{A C K N OW LE D G MENTS}

We thank P. Giguère and D. Drolet for technical assistance and D. Rodriguez for reconstruction of intracellularly stained RE neurons.

\section{G R A N T S}

This work was supported by grants from the Canadian Institutes for Health Research (CIHR) (MT-3689, MOP-36545, and MOP-37862). I. Timofeev is a Scholar of CIHR.

\section{R E F E R E N C E S}

Alzheimer C, Schwindt PC, and Crill WE. Modal gating of $\mathrm{Na}^{+}$channels as a mechanism of persistent $\mathrm{Na}^{+}$current in pyramidal neurons from rat and cat sensorimotor cortex. J Neurosci 13: 660-673, 1993.

Bal T, von Krosigk M, and McCormick DA. Synaptic and membrane mechanisms underlying synchronized oscillations in the ferret lateral geniculate nucleus in vitro. $J$ Physiol 483: 641-663, 1995a. 
Bal T, von Krosigk M, and McCormick DA. Role of the ferret perigeniculate nucleus in the generation of synchronized oscillations in vitro. J Physiol 483: 665-685, $1995 b$.

Bazhenov M, Timofeev I, Steriade M, and Sejnowski TJ. Cellular and network models for intrathalamic augmenting responses during $10-\mathrm{Hz}$ stimulation. J Neurophysiol 79: 2730-2748, 1998.

Bazhenov M, Timofeev I, Steriade M, and Sejnowski TJ. Patterns of spiking-bursting activity in the thalamic reticular nucleus initiate sequences of spindle oscillations in thalamic network. J Neurophysiol 84: 1076-1087, 2000.

Bennett DJ, Hultborn H, Fedirchuk B, and Gorassini M. Synaptic activation of plateaus in hindlimb motoneurons of decerebrate cats. J Neurophysiol 80: 2023-2037, 1998.

Chuang SC, Bianchi R, and Wong RK. Group I mGluR activation turns on a voltage-gated inward current in hippocampal pyramidal cells. J Neurophysiol 83: 2844-2853, 2000.

Contreras D, Curró Dossi R, and Steriade M. Bursting and tonic discharges in two classes of reticular thalamic neurons in vivo. $J$ Neurophysiol 68 : 973-977, 1992.

Contreras D, Curró Dossi R, and Steriade M. Electrophysiological properties of cat reticular thalamic neurons in vivo. J Physiol 470: 273-294, 1993

Contreras D and Steriade M. Spindle oscillation: the role of corticothalamic feedback in a thalamically generated rhythm. J Physiol 490: 159-179, 1996

Crill WE. Persistent sodium current in mammalian central neurons. Annu Rev Physiol 58: 349-362, 1996.

Crunelli V, Kelly JS, Leresche N, and Pirchio M. The ventral and dorsal lateral geniculate nucleus of the rat: intracellular recordings in vitro. J Physiol 384: 587-601, 1987.

Destexhe A, Mainen ZF, and Sejnowski TJ. Synthesis of models for excitable membranes, synaptic transmission and neuromodulation using a common kinetic formalism. J Comput Neurosci 1: 195-230, 1994.

Destexhe A, Bal T, McCormick DA, and Sejnowski TJ. Ionic mechanisms underlying synchronized oscillations and propagating waves in a model of ferret thalamic slices. J Neurophysiol 76: 2049-2070, 1996a.

Destexhe A, Contreras D, Steriade M, and Huguenard JR In vivo, in vitro and computational analysis of dendritic calcium currents in thalamic reticular neurons. J Neurosci 16: 169-185, 1996 b.

Domich L, Oakson G, and Steriade M. Thalamic burst patterns in the naturally sleeping cat: a comparison between cortically projecting and reticularis neurons. J Physiol 379: 429-449, 1986.

Dutar $\mathbf{P}$ and Nicoll RA. A physiological role for $\mathrm{GABA}_{\mathrm{B}}$ receptors in the central nervous system. Nature 332: 156-158, 1988.

Fricker D and Miles R. EPSP amplification and the precision of spike timing in hippocampal neurons. Neuron 28: 559-569, 2000.

Gola M, Delmas P, and Chagneux H. Encoding properties induced by a persistent voltage-gated muscarinic sodium current in rabbit sympathetic neurons. J Physiol 510: 387-399, 1998.

Heyward P, Ennis M, Keller A, and Shipley MT Membrane bistability in olfactory bulb mitral cells. J Neurosci 21: 5311-5320, 2001.

Hughes SW, Cope DW, Toth TI, Williams SR, and Crunelli V All thalamocortical neurons possess a T-type $\mathrm{Ca}^{2+}$ "window" current that enables the expression of bistability-mediated activities. J Physiol 517: 805-815, 1999.

Huguenard JR. Low-threshold calcium currents in central nervous system neurons. Annu Rev Physiol 58: 329-348, 1996.

Huguenard JR and McCormick DA. Simulation of the currents involved in rhythmic oscillations in thalamic relay neurons. J Neurophysiol 68: 1373$1383,1992$.
Huguenard JR and Prince DA. A novel T-type current underlies prolonged $\mathrm{Ca}^{2+}$-dependent burst firing in GABAergic neurons of rat thalamic reticular nucleus. J Neurosci 12: 3804-3817, 1992.

Jones EG. The Thalamus. New York: Plenum, 1985.

Kim $\mathbf{U}$ and McCormick DA. Functional and ionic properties of a slow afterhyperpolarization in ferret perigeniculate neurons in vitro. $J$ Neurophysiology 80: 1222-1235, 1998a.

Kim U and McCormick DA. The functional influence of burst and tonic firing mode on synaptic interactions in the thalamus. J Neurosci 18: 9500-9516, 1998 b.

Llinás R and Sugimori M. Electrophysiological properties of in vitro Purkinje cell somata in mammalian cerebellar slices. J Physiol 305: 171-195, 1980.

McCormick DA and Pape HC. Properties of a hyperpolarization-activated cation current and its role in rhythmic oscillation in thalamic relay neurons. J Physiol 431: 291-318, 1990.

Paré D and Lang EJ. Calcium electrogenesis in neocortical pyramidal neurons in vivo. Eur J Neurosci 10: 3164-3170, 1998.

Perkins KL and Wong RK. Intracellular QX-314 blocks the hyperpolarization-activated inward current $I_{\mathrm{q}}$ in hippocampal CA1 pyramidal cells. J Neurophysiol 73: 911-915, 1995.

Schwindt $\mathbf{P}$ and Crill W. Mechanisms underlying burst and regular spiking evoked by dendritic depolarization of layer 5 cortical pyramidal neurons. J Neurophysiol 81: 1341-1354, 1999.

Scott DW. On optimal and data-based histograms. Biometrika 5-610, 1979.

Steriade M, Deschênes M, Domich L, and Mulle C. Abolition of spindle oscillations in thalamic neurons disconnected from nucleus reticularis thalami. J Neurophysiol 54: 1473-1497, 1985.

Steriade M, Domich L, and Oakson G. Reticularis thalami neurons revisited: activity changes during shifts in states of vigilance. J Neurosci 6: 68-81, 1986.

Steriade M, Domich L, Oakson G, and Deschênes M. The deafferented reticularis thalami nucleus generates spindle rhythmicity. J Neurophysiol 57: 260-273, 1987.

Steriade M, Jones EG, and Llinás RR. Thalamic Oscillations and Signaling. New York: Wiley-Interscience, 1990.

Steriade M, McCormick DA, and Sejnowski TJ. Thalamocortical oscillation in the sleeping and aroused brain. Science 262: 679-685, 1993.

Svoboda K, Denk W, Kleinfeld D, and Tank DW. In vivo dendritic calcium dynamics in neocortical pyramidal neurons. Nature 385: 161-165, 1997.

Talbot MJ and Sayer RJ. Intracellular QX-314 inhibits calcium currents in hippocampal CA1 pyramidal neurons. J Neurophysiol 76: 2120-2124, 1996.

Timofeeev I and Steriade M. Low-frequency rhythms in the thalamus of intact-cortex and decorticated cats. J Neurophysiol 76: 4152-4168, 1996.

Timofeev I, Bazhenov M, Sejnowski TJ, and Steriade M. Contribution of intrinsic and synaptic factors in the desynchronization of thalamic oscillatory activity. Thalamus Relat Syst 1: 53-69, 2001.

Thomson AM. Inhibitory postsynaptic potentials evoked in thalamic neurons by stimulation of the reticularis nucleus evoke slow spikes in isolated rat brain slices. Neuroscience 25: 491-502, 1988.

Toth TI, Hughes SW, and Crunelli V. Analysis and biophysical interpretation of bistable behavior in thalamocortical neurons. Neuroscience 87 . 519-523, 1998.

von Krosigk M, Bal T, and McCormick DA. Cellular mechanisms of a synchronized oscillation in the thalamus. Science 261: 361-364, 1993.

Williams SR, Toth TI, Turner JP, Hughes SW, and Crunelli V. The "window" component of the low threshold $\mathrm{Ca}^{2+}$ current produces input signal amplification and bistability in cat and rat thalamocortical neurons. J Physiol 505: 689-705, 1997. 